\title{
Desempenho agronômico de genótipos de amendoim sob alta severidade de mancha anelar na Alta Paulista
}

Submetido- 07 jul. $2020 \quad$ Aprovado - 07 ago. $2020 \quad$ Publicado - 14 out. 2020
dol http://dx.doi.org/10.17648/sas.v1i1.6

Amenco Peanuts, marcel.rodrigo@amenco.com.br, Tupã, SP.

Marcel Rodrigo Bazanella (D)

Programa de Melhoramento do Amendoim - Embrapa, Santo Antônio de Goiás, GO

jair.heuert@embrapa.br.

Beatrice Peanuts, Tupã, SP; rodolfo@beatricepeanuts.com.

Rodolfo Pires Ribeiro (D)

Jair Heuert (D)

Taís de Moraes Falleiro Suassuna (D)
$\begin{aligned} & \text { Programa de Melhoramento do Amendoim - Embrapa, Santo Antônio de Goiás, GO, } \\ & \text { tais.suassuna@embrapa.br. }\end{aligned}$

Victor Hugo Lanças Zammataro (D)

Casul Peanuts - Cooperativa Agropecuária de Parapuã, Parapuã, SP, victorhugo@casul.com.br.

\section{RESUMO}

A cultura do amendoim possui grande relevância na atividade agroindustrial na região da Alta Paulista no estado de São Paulo. $O$ objetivo da presente pesquisa foi avaliar desempenho agronômico de genótipos de amendoim na Alta Paulista, sob alta severidade de mancha anelar. O ensaio foi semeado no dia 15 de novembro de 2019, época de fechamento de semeadura do amendoim, no município de Tupã-SP. $O$ delineamento utilizado foi em blocos casualizados, com 4 repetições. Os tratamentos foram treze genótipos de amendoim, sendo doze linhagens avançadas: 17-1253 OL, 18-1952 OL, 18-1968 OL, 18-1969 OL, 18-2053 OL, 18-2087 OL, 18-2091 OL, 18-2101 OL, 18-2136 OL, 18-2182 OL, 18-2246 OL, 18-2250 OL e a cultivar: BRS 423 OL, desenvolvidas pelo Programa de Melhoramento do Amendoim da Embrapa. As parcelas foram constituídas por duas linhas de três metros de comprimento, espaçamento de noventa centímetros entre linhas, intervalo de dois metros entre parcelas e estande de 17 plantas por metro linear. Foram avaliadas: severidade de mancha anelar, massa de 100 grãos e produtividade de vagens, com diferença significativa em todas variáveis em relação aos diferentes genótipos. Os genótipos 18-2250 OL, 18-2136 OL e 18-2101 OL apresentaram as menores notas de severidade da mancha anelar. As maiores produtividades foram obtidas nos genótipos 18-2250 OL, 18-2136 OL, 18-1969 OL, 18-2101 OL e 18-2259 OL. Considerando a severidade da mancha anelar e produtividade, recomenda-se os genótipos 18-2250 OL, 18-2136 OL e 18-2101 OL para cultivo na região da Alta Paulista.

Palavras-chave: Arachis hypogaea L.; Programa de Melhoramento; Viroses.

\section{Agronomic performance of peanut genotypes under high severity of ring spot in Alta Paulista}

\section{ABSTRACT}

The peanut culture has great relevance in the agro-industrial activity in the Alta Paulista region in the state of São Paulo. The objective of this research was to evaluate the agronomic performance of peanut genotypes in Alta Paulista, under high severity of ring spot. The trial was sown on November 15, 2019, the closing date for peanut sowing, in the municipality of Tupã-SP. The design used was in randomized blocks, with 4 repetitions. The treatments were thirteen peanut genotypes, being twelve advanced strains: 17-1253 OL, 18-1952 OL, 18-1968 OL, 
18-1969 OL, 18-2053 OL, 18-2087 OL, 18-2091 OL, 18- 2101 OL, 18-2136 OL, 18-2182 OL, 18-2246 $O L, 18-2250$ OL and a cultivar: BRS 423 OL, developed by Embrapa's Peanut Breeding Program. The plots consisted of two lines of three meters in length, spacing of ninety centimeters between lines, an interval of two meters between plots and a stand of 17 plants per linear meter. The following were evaluated: severity of ring spot, mass of 100 grains and yield of pods, with significant difference in all variables in relation to the different genotypes. The genotypes 18$2250 O L, 18-2136$ OL and 18-2101 OL had the lowest annotation severity scores. The highest yields were obtained in the genotypes 18-2250 OL, 18-2136 OL, 18-1969 OL, 18-2101 OL and 18$2259 O L$. Considering the severity of the ring spot and productivity, genotypes 18-2250 OL, 18$2136 \mathrm{OL}$ and 18-2101 OL are recommended for cultivation in the Alta Paulista region.

Keywords: Arachis hypogaea L.; Improvement Program; Viruses.

\title{
Rendimiento agronómico de genotipos de maní bajo alta severidad de la mancha de anillo en Alta Paulista
}

\author{
RESUMEN
}

El cultivo del maní tiene gran relevancia en la actividad agroindustrial de la región de la Alta Paulista del estado de São Paulo. El objetivo de esta investigación fue evaluar el desempeño agronómico de los genotipos del maní en Alta Paulista, bajo la alta severidad de la mancha anular. El juicio fue sembrado el 15 de noviembre de 2019, cuando se cerró la siembra de maní en el municipio de Tupã-SP. El diseño utilizado fue en bloques aleatorios, con 4 repeticiones. Los tratamientos fueron trece genotipos de maní, doce cepas avanzadas: 17-1253 OL, 18-1952 OL, 18-1968 OL, 18-1969 OL, 18-2053 OL, 18-2087 OL, 18-2091 OL, 18-2101 OL, 18-2136 OL, 182182 OL, 18-2246 OL, 18-2250 OL y un cultivar: BRS 423 OL, desarrollado por el Programa de Mejora de maní de Embrapa. Las parcelas estaban formadas por dos líneas de tres metros de largo, un espacio de noventa centímetros entre líneas, un intervalo de dos metros entre parcelas y un rodal de 17 plantas por metro lineal. Se evaluó la severidad de la mancha anular, la masa de 100 granos y la productividad de las vainas, con una diferencia significativa en todas las variables en relación con los diferentes genotipos. Los genotipos 18-2250 OL, 18-2136 OL y 18-2101 OL mostraron las notas más bajas de severidad de la mancha anular. Los mayores rendimientos se obtuvieron en los genotipos 18-2250 OL, 18-2136 OL, 18-1969 OL, 182101 OL y 18-2259 OL. Teniendo en cuenta la gravedad de la mancha anular y la productividad, se recomienda el cultivo de los genotipos 18-2250 OL, 18-2136 OL y 18-2101 OL en la región de la Alta Paulista.

Palabras clave: Arachis hypogaea L.; Programa de Mejora; Virus.

\section{Introdução}

O amendoim é um produto importante na atividade agroindustrial da região Alta Paulista, no oeste do estado de São Paulo (BAZANELLA et al., 2019). Nos últimos anos, epidemias de mancha anelar, conhecida popularmente como virose, foram relatadas nessa região, causando prejuízos em algumas áreas em função da redução na produção. Programa de Melhoramento do Amendoim da Embrapa, desenvolve cultivares competitivas no mercado, adaptadas à região de cultivo e que tenham tolerância as principais doenças da cultura do amendoim (RIBEIRO et al., 2017). 
O Tospovirus, da família Bunyaviridae, espécies Groundnut Ringspot Virus (GRSV) e Tomato Chlorotic Spot Virus (TCSV), conhecidos como vírus da mancha anelar do amendoim, são transmitidos pelo inseto vetor tripes (PETERS, 2003). Diferentes estratégias de manejo devem ser adotadas para controlar o tripes para manter a cultura com alta produção, sem grandes aumentos nos custos de produção (PEROZINI et al., 2014). Uma das formas mais econômicas para reduzir os danos é adotar cultivares que possuem resistência ou tolerância ao vírus (CULBREATH et al., 2003).

Nos últimos anos, epidemias de mancha anelar tem sido frequentes em áreas de produção em São Paulo (RIBEIRO et al., 2019). Os sintomas descritos da mancha anelar são: clareamento das nervuras, mosaico e afundamento do tecido internerval, anéis cloróticos, necrose na parte apical, crescimento atrofiado sem expressão de produtividade, manchas e rachaduras na película, além de apresentar grãos avermelhados (SUASSUNA et al., 2017). Com isso, a identificação de genótipos resistentes é necessária para diminuir os impactos econômicos dessa doença em situações de epidemias severas nas lavouras.

O trabalho teve como objetivo avaliar desempenho agronômico de genótipos de amendoim na Alta Paulista, sob alta severidade de mancha anelar, sendo treze genótipos desenvolvidos pelo Programa de Melhoramento do Amendoim da Embrapa.

\section{Material e métodos}

O ensaio foi semeado no dia 15 de novembro de 2019, em uma área precedida de amendoim, no munícipio de Tupã-SP. Utilizou-se delineamento de blocos casualizados, com quatro repetições. Os tratamentos foram constituídos de treze genótipos de amendoim, sendo doze linhagens avançadas: 17-1253 OL, 18-1952 OL, 18-1968 OL, 18-1969 OL, 18-2053 OL, 18-2087 OL, 18-2091 OL, 18-2101 OL, 18-2136 OL, 18-2182 OL, 182246 OL, 18-2250 OL e uma cultivar: BRS $423 \mathrm{OL}$, desenvolvidas pelo Programa Melhoramento do Amendoim da Embrapa. As parcelas foram constituídas por duas linhas de três metros de comprimento, espaçamento 
de noventa centímetros entre linhas, intervalo de três metros entre parcelas e estande de 17 plantas por metro linear. $\mathrm{Na}$ condução do ensaio, foram utilizados os tratos culturais recomendados para a cultura do amendoim (correção do solo, aplicação de gesso, manejo fitossanitário de pragas e doenças).

A colheita foi realizada aos 122 dias após a semeadura usando um arrancador duplo da marca Agromérica $\AA$. A severidade da mancha anelar na área experimental foi avaliada conforme a escala diagramática, com notas de 0 a 5 , em que 0 indica a planta sem sintomas e 5 nanismo severo (BALDESSARI, 2008). Também foram avaliadas a produtividade de vagens $\left(\mathrm{kg} / \mathrm{ha}^{-1}\right)$ e a massa de 100 grãos $(\mathrm{g})$. Os dados foram submetidos à análise de variância pelo Teste $\mathrm{F}$ e as médias dos tratamentos foram comparados pelo teste de Scott-Knott, no nível de 5\% de probabilidade, por meio do programa computacional SISVAR 5.6 (FERREIRA, 2019).

\section{Resultados e discussão}

Foram observadas diferenças significativas entre os tratamentos para todas as variáveis analisadas (Tabela 1). A severidade da mancha anelar no ensaio obteve nota média de 2,4. O genótipo 18-2250 OL obteve menor nota $(0,3)$, resultando em um genótipo consideravelmente tolerante. Os genótipos 18-2136 OL $(1,0)$ e 18-2101 OL $(0,9)$ apresentaram intermediária tolerância a mancha anelar. Os demais genótipos do presente estudo apresentaram notas entre 1,5 e 4,5. Ribeiro et al. (2019), observaram notas 0,6 e 1,7 com os genótipos 18-2136 OL e 18-2101 OL, respectivamente, em Tupã-SP.

Para massa de 100 grãos, verificou-se diversidade de tamanho de grãos, com os genótipos 18-1969 OL (81,3 g), 18-1952 OL (80,6 g) e 17$1253 \mathrm{OL}(80,2 \mathrm{~g})$, sendo-os com as maiores massas e o genótipo 19-2091 OL $(70,8)$ com a menor, resultando numa diferença de $10,5 \mathrm{~g}$ entre os extremos. Resultados semelhantes ao presente estudo foram obtidos por Martins et al. (2019), que estudando o desempenho de linhagens de amendoim no Cerrado, observou massa semelhante com o genótipo 18- 
1952 OL (78,4 g). Aparecido Filho et al. (2019), nas condições do Mato Grosso do Sul, obtiveram com BRS $423 \mathrm{OL}$ uma massa de $77,1 \mathrm{~g}$, semelhante a obtida no presente estudo $(79,0 \mathrm{~g})$.

Tabela 1. Severidade de mancha anelar (nota), massa de 100 grãos (g) e produtividade de vagens ( $\mathrm{kg} / \mathrm{ha}^{-1}$ e sacas/alqueire ${ }^{-1}$ ) em função de diferentes genótipos de amendoim na Alta Paulista. Tupã-SP, 2019/20.

\begin{tabular}{|c|c|c|c|c|}
\hline \multirow{2}{*}{ Genótipos } & \multirow{2}{*}{$\begin{array}{c}\begin{array}{c}\text { Severidade de } \\
\text { mancha anelar }\end{array} \\
\text { (nota) }\end{array}$} & \multirow{2}{*}{$\begin{array}{c}\text { Massa de } \\
100 \text { grãos } \\
\text { (g) }\end{array}$} & \multicolumn{2}{|c|}{ Produtividade de vagens } \\
\hline & & & $\left(\mathrm{kg}^{\prime} \mathrm{ha}^{-1}\right)$ & $\left(\right.$ (sacas/alqueire $\left.^{-1}\right)$ \\
\hline $18-2250 \mathrm{OL}$ & $0,3 a$ & $74,9 \mathrm{~d}$ & $5.113,4 \mathrm{a}$ & 495,0 \\
\hline $18-2136 \mathrm{OL}$ & $1,0 \mathrm{~b}$ & $77,0 \mathrm{c}$ & $4.867,2 \mathrm{a}$ & 471,2 \\
\hline $18-1969 \mathrm{OL}$ & $1,6 \mathrm{c}$ & $81,3 a$ & $4.645,8 \mathrm{a}$ & 449,7 \\
\hline $18-2101 \mathrm{OL}$ & $0,9 \mathrm{~b}$ & $75,5 d$ & $4.572,8 \mathrm{a}$ & 442,6 \\
\hline 18-2259 OL & $2,3 d$ & $76,1 \mathrm{c}$ & $3.898,4 \mathrm{a}$ & 377,4 \\
\hline 18-1952 OL & $2,8 \mathrm{e}$ & 80,6 a & $3.659,6$ b & 354,2 \\
\hline 18-2053 OL & $2,6 \mathrm{e}$ & $74,6 \mathrm{~d}$ & $3.596,0 \mathrm{~b}$ & 348,2 \\
\hline 18-2182 OL & $2,2 d$ & 73,7 e & $3.512,1 \mathrm{~b}$ & 340,0 \\
\hline BRS $423 \mathrm{OL}$ & $2,0 \mathrm{c}$ & $79,0 \mathrm{~b}$ & $3.378,4$ b & 327,1 \\
\hline $17-1253 \mathrm{OL}$ & $3,4 \mathrm{~b}$ & $80,2 \mathrm{a}$ & $2.944,1$ b & 285,0 \\
\hline 18-2246 OL & $2,6 \mathrm{e}$ & $76,1 \mathrm{c}$ & $2.786,3$ b & 269,8 \\
\hline 18-1968 OL & $3,0 \mathrm{e}$ & $76,0 \mathrm{c}$ & $2.542,8$ b & 246,2 \\
\hline $18-2087$ OL & $4,2 \mathrm{~g}$ & 73,7 e & $2.304,6 \mathrm{~b}$ & 223,1 \\
\hline 18-2091 OL & $4,1 \mathrm{~g}$ & $70,8 \mathrm{f}$ & $1.846,3 \mathrm{~b}$ & 178,8 \\
\hline Média & 2,4 & 76,4 & $3.547,7$ & 333,77 \\
\hline CV (\%) & 15,0 & 1,2 & 25,1 & - \\
\hline $\mathrm{Pr}>\mathrm{Fc}$ & $>0,0001^{*}$ & $>0,0001^{*}$ & $>0,0001^{*}$ & - \\
\hline
\end{tabular}

Em relação a produtividade de vagens, os genótipos 18-2250 OL (5.113,3 kg/ha-1), 18-2136 OL (4.867,2 kg/ha-1), 18-1969 OL $\left(4.645,8 \mathrm{~kg} / \mathrm{ha}^{-}\right.$ $\left.{ }^{1}\right), 18-2101 \mathrm{OL}\left(4.572,8 \mathrm{~kg} / \mathrm{ha}^{-1}\right)$ e $18-2259 \mathrm{OL}\left(3.898,4 \mathrm{~kg} / \mathrm{ha}^{-1}\right)$ foram os mais produtivos em relação aos demais, ambos apresentaram produtividade superior a $3.800 \mathrm{~kg} / \mathrm{ha}^{-1}$. Os genótipos $17-1253 \mathrm{OL}\left(2.944,1 \mathrm{~kg} / \mathrm{ha}^{-1}\right), 18-$ $2246 \mathrm{OL}\left(2.786,1 \mathrm{~kg} / \mathrm{ha}^{-1}\right), 18-1968 \mathrm{OL}\left(2.542,8 \mathrm{~kg} / \mathrm{ha}^{-1}\right), 18-2087 \mathrm{OL}$ $\left(2.304,6 \mathrm{~kg} / \mathrm{ha}^{-1}\right)$ e $18-2091 \mathrm{OL}\left(1.846,3 \mathrm{~kg} / \mathrm{ha}^{-1}\right)$, obtiveram produtividades inferiores a $3.000 \mathrm{~kg} / \mathrm{ha}^{-1}$ e a cultivar BRS $423 \mathrm{OL}\left(3.378,4 \mathrm{~kg} / \mathrm{ha}^{-1}\right)$. Martins et al. (2019), observaram que o genótipo 18-2136 OL entre os mais produtivos em Santo Antônio de Goiás-GO. Observa-se que os genótipos 
18-2250 OL, 18-2136 OL e 18-2101 OL estiveram entre as menores notas de severidade de mancha anelar e maiores produtividades de vagens, demonstrando boas características de adaptação as condições edafoclimáticas da Alta Paulista.

\section{Conclusões}

Os genótipos 18-2250 OL, 18-2136 OL e 18-2101 OL apresentaram as menores notas de severidade da mancha anelar. As maiores produtividades foram obtidas nos genótipos 18-2250 OL, 18-2136 OL, 181969 OL, 18-2101 OL e 18-2259 OL. Considerando a severidade da mancha anelar e produtividade, os genótipos 18-2250 OL, 18-2136 OL e 18-2101 OL são os mais propícios para cultivo na região da Alta Paulista.

\section{Agradecimentos}

Os autores agradecem à Amenco Agroindustrial pela cooperação técnica, suporte financeiro e aos produtores Antônio Fernandes e Ricardo da Silveira Fernandes, pela disponibilidade da área em Tupã-SP. 


\section{Referências}

APARECIDO FILHO, A. C.; RODRIGUES, C. R.; HEUERT, J.; MARTINS, K. B. B.; SUASSUNA, T. M. F.; SOUZA, T. C. Desempenho de cultivares de amendoim nas condições do Mato Grosso do Sul. In: Anais do Encontro Sobre a Cultura do Amendoim, 16., 2019, Jaboticabal. Anais eletrônicos... Campinas: GALOÁ, 2019. Disponível em: $<$ https://proceedings.science/encontro-amendoim-2019/papers/desempenhode-cultivares-de-amendoim-nas-condicoes-do-mato-grosso-do-sul>. Acesso em: 25 abr. 2020.

BALDESSARI, J. J. (2008). Genetics of Tomato Spotted Wilt Virus in Peanut (Arachis hypogaea L.). Ph.D. thesis, University of Florida, Gainesville, FL.

BAZANELLA, M. R.; HEUERT, J.; MARTINS, K. B. B.; SUASSUNA, T. M. F.; DEUS, T. J. Desempenho de genótipos de amendoim na Alta Paulista com avaliação de perdas na colheita. In: Anais do Encontro Sobre a Cultura do Amendoim, 16., 2019, Jaboticabal. Anais eletrônicos... Campinas: GALOÁ, 2019. Disponível em: <https://proceedings.science/encontro-amendoim2019/papers/desempenho-de-genotipos-de-amendoim-na-alta-paulista-comavaliacao-de-perdas-na-colheita>. Acesso em: 25 abr. 2020.

CULBREATH, A. K.; TODD, J. W.; BROWN, S. L. Epidemiology and management of tomato spotted wilt in peanut. Annual Review of Phytopathology, v. $41, \quad$ n. $1, \quad$ p. $53-75,2003$. 10.1146/annurev.phyto.41.052002.095522.

FERREIRA, D. F. SISVAR: a computer analysis system to fixed effects split plot type designs. Revista Brasileira de Biometria, [S.L.], v. 37, n. 4, p. 529, 20 dez. 2019. http://dx.doi.org/10.28951/rbb.v37i4.450.

MARTINS, K. B. B.; RODRIGUES, L. L.; HEUERT, J.; XAVIER, M. F. N.; SUASSUNA, T. M. F.; BETIOL, R. A. B. Desempenho agronômico de novas linhagens de amendoim no Cerrado. In: Anais do Encontro Sobre a Cultura do Amendoim, 16., 2019, Jaboticabal. Anais eletrônicos... Campinas: GALOÁ, 2019. Disponível em: <https://proceedings.science/encontroamendoim-2019/papers/desempenho-agronomico-de-novas-linhagens-deamendoim-no-cerrado>. Acesso em: 25 abr. 2020.

PEROZINI, A. C.; SILVA, P. S.; GOUSSAIN, R. C. S. Resistência ao tripes Enneothrips flavens Moulton (Thysanoptera: Thripidae) e o potencial produtivo em genótipos de amendoim de hábito de crescimento rasteiro. Vértices, v. 16, n. 2, p. 79-92, 2014. https://doi.org/10.5935/1809$\underline{2667.20140019}$

PETERS, D. Tospoviruses. In: Viruses and vírus-like diseases of major crops in developing countries. Kluwer Academic Publishers, v. 20, p. 719-742, 2003. 
RIBEIRO, R. P.; HEUERT, J.; SUASSUNA, N. D.; SUASSUNA, T. M. F. Desempenho de linhagens de amendoim sob alta severidade de doenças foliares. In: Anais do encontro sobre a cultura do amendoim, 14., 2017, Jaboticabal. Anais eletrônicos... Campinas: GALOÁ, 2017. Disponível em: $<$ https://proceedings.science/encontro-amendoim-2017/papers/desempenhode-linhagens-de-amendoim-sob-alta-severidade-de-doencasfoliares?lang=pt-br>. Acesso em: 02 jun. 2020.

RIBEIRO, R. P.; HEUERT, J.; SOAVE, J. H.; SANTOS, L. C. C.; SUASSUNA, T. M. F. Avaliação de severidade de mancha preta e mancha anelar em diferentes genótipos de amendoim na região da Alta Paulista. In: Anais do Encontro Sobre a Cultura do Amendoim, 16., 2019, Jaboticabal. Anais eletrônicos... Campinas: GALOÁ, 2019. Disponível em: <https://proceedings.science/encontro-amendoim-2019/papers/avaliacao-deseveridade-de-mancha-preta-e-mancha-anelar-em-diferentes-genotipos-deamendoim-na-regiao-da-alta-paulista>. Acesso em: 23 abr. 2020.

SUASSUNA, T. M. F.; ALMEIDA, M. M. S.; RESENDE, R. O.; LIMA, M. G. A.; FARIA, J. C.; HEUERT, J.; SUASSUNA, N. D. Identificação de Tospovirus em amostras de amendoim com sintomas de clareamento nas nervuras no estado de Goiás. In: Anais do encontro sobre a cultura do amendoim, 13., 2016, Jaboticabal. Anais eletrônicos... Campinas: GALOÁ, 2016.

Disponível em: <https://www.researchgate.net/publication/333951206_IDENTIFICACAO_DE _TOSPOVIRUS_EM_AMOSTRAS_DE_AMENDOIM_COM_SINTOMAS_DE _CLAREAMENTO_DAS_NERVURAS_NO_ESTADO_DE_GOIAS>. Acesso em: 25 abr. 2020. 